Збірник наукових праць Української державної академії залізничного транспорту

УДК 656.212.5

Д-р техн. наук О.М. Огар

Doct. of techn. sciences O.M. Ogar

\title{
МАТЕМАТИЧНА МОДЕЛЬ ВИЗНАЧЕННЯ РАЦІОНАЛЬНИХ ПАРАМЕТРІВ ПОЗДОВЖНЬОГО ПРОФІЛЮ НАСУВНОЇ ЧАСТИНИ СОРТУВАЛЬНИХ ГІРОК
}

\section{MATHEMATICAL MODEL OF SORTING HUMPS SLIP-ON PART LONGITUDINAL PROFILE RATIONAL PARAMETERS DETERMINATION}

Постановка проблеми у загальному вигляді, іiї зв'язок 3 важливими науковими та практичними завданнями. Однією з головних проблем залізничного транспорту України $\epsilon$ проблема ресурсозбереження. Ним щорічно споживається до $5 \%$ електроенергії, що виробляється, і до 10 \% дизельного палива. Суттєвий вплив на витрати паливно- енергетичних ресурсів мають технологія роботи, система управління, стан і конструкція засобів транспорту. Поряд 3 цим перераховані фактори значною мірою визначають i ступінь використання перевізних і виробничих ресурсів (вагонів, технічних засобів, що забезпечують виконання технологічного процесу, тощо). Виходячи 3 цього дослідження процесу 
функціонування i конструктивнотехнологічних параметрів сортувальних гірок слід спрямовувати на раціональне використання паливно-енергетичних, виробничих i перевізних ресурсів при дотриманні встановлених технічних i технологічних вимог.

Аналіз останніх досліджень i публікацій. Питанням удосконалення конструкції поздовжнього профілю насувної частини приділено недостатньо уваги. Останні дослідження в основному спрямовані на створення імітаційних моделей насуву і розпуску составів з метою визначення витрат паливно-енергетичних ресурсів та оптимізації режимів роботи маневрових локомотивів [1-4]. У минулому сторіччі удосконаленням параметрів профілю насувної частини займались такі вчені як, В.С. Павлов, Л.Б. Тишков, В.Ф. Пригоровський, О.П. Шипулін та ін. [5-8]. Головним і загальним недоліком виконаних зазначеними вченими досліджень $є$ відсутність ресурсозберігаючого підходу при оптимізації поздовжнього профілю.

Мета дослідження. Метою даних досліджень $є$ забезпечення заощадження паливно-енергетичних ресурсів при виконанні

технологічного

операцій

процесу

гіркового

удосконалення наукового підходу до розрахунку раціональних параметрів поздовжнього профілю насувної частини сортувальних гірок.

Основна частина. У рамках вирішення проблеми ресурсозбереження визначення раціональних параметрів поздовжнього профілю насувної частини повинно здійснюватись за умови мінімізації витрат дизельного палива (електроенергіi) на насув i розпуск составів. При цьому пропонується:

1) розглянути завдання раціоналізації конструкції профілю на прикладі використання у гірковому технологічному процесі маневрових тепловозів ЧМЕ-3;

2) для підвищення достовірності результатів моделювання використовувати осьову модель вагона та окремо враховувати додатковий питомий опір від середовища і вітру;

3) розглянути двохелементну конструкцію поздовжнього профілю.

При допущенні про постійність швидкості та напрямку вітру протягом насуву та розпуску состава його рух можна описати диференціальним рівнянням

$$
\frac{d V}{d t}=g^{\prime}(S) \cdot\left(\begin{array}{l}
f_{m}\left(V\left(I_{1}^{\text {нас }}, I_{2}^{\text {нас }}\right)\right)+I_{\text {екв }}\left(S, I_{1}^{\text {нас }}, I_{2}^{\text {нас }}\right)-\omega_{0}^{\text {лок }}\left(V\left(I_{1}^{\text {нас }}, I_{2}^{\text {нас }}\right)\right)- \\
-\omega_{0}^{\text {сост }}(S)-\omega_{c \kappa}\left(S, V\left(I_{1}^{\text {нас }}, I_{2}^{\text {нас }}\right)\right)-\omega_{c в}\left(S, V\left(I_{1}^{\text {нас }}, I_{2}^{\text {нас }}\right)\right)
\end{array}\right) \cdot 10^{-3},
$$

де $g^{\prime}(S)$ - прискорення вільного падіння 3 урахуванням моменту інерції мас, що обертаються, локомотива і вагонів состава, м/ $\mathrm{c}^{2}$;

$f_{m}\left(V\left(I_{1}^{\text {нас }}, I_{2}^{\text {нас }}\right)\right)$ - миттєва питома сила тяги локомотива, $\mathrm{H} / к \mathrm{H}$;

$$
V\left(I_{1}^{\text {нас }}, I_{2}^{\text {нас }}\right) \quad \text { - миттева швидкість }
$$

состава, що насувається або розпускається 3 гірки, м/с;

$I_{1}^{\text {нас }}, I_{2}^{\text {нас }}$ - крутість відповідно першого і другого елементів поздовжнього профілю, $\%$
$I_{\text {екв }}\left(S, I_{1}^{\text {нас }}, I_{2}^{\text {нас }}\right) \quad$ - миттєва крутість еквівалентного уклону, \% ;

$S$ - шлях, що пройдено локомотивом 3 вагонами 3 моменту початку насуву состава на гірку, м;

$$
\omega_{0}^{\text {лок }}\left(V\left(I_{1}^{\text {нас }}, I_{2}^{\text {нас }}\right)\right)-\text { миттєвий основний }
$$
питомий опір гіркового локомотива, $\mathrm{H} / \kappa \mathrm{H}$;

$\omega_{0}^{\text {cocm }}(S)$ - основний питомий опір состава, $\mathrm{H} / \mathrm{\kappa H}$;

$\omega_{c \kappa}\left(S, V\left(I_{1}^{\text {нас }}, I_{2}^{\text {нас }}\right)\right), \omega_{c в}\left(S, V\left(I_{1}^{\text {нас }}, I_{2}^{\text {нас }}\right)\right)_{-}$ миттєвий додатковий питомий опір руху 
локомотива і состава відповідно від стрілок і кривих, середовища і вітру, Н/кН.

У загальному випадку цільова функція має такий аналітичний вигляд:

$$
G_{n}=\sum_{i=1}^{r} B_{2} \cdot \Delta t \rightarrow G_{n \min }
$$

де $G_{n}$ - витрати дизельного палива, кг;

$r$ - число проміжків часу $(\Delta t)$ від початку насуву до закінчення розпуску;

$B_{2}$ - витрати палива за одиницю часу, кг/с.

Цільову функцію (2) можна розкласти на таку суму добутків:

$$
\begin{aligned}
& G_{n}=B_{2_{X X}} \cdot t_{X X}+B_{2_{1 \Pi}} \cdot t_{1 \Pi}+\ldots+B_{2_{8 \Pi}} \cdot t_{8 \Pi}=B_{2_{X X}} \cdot\left(\int_{t_{0}^{X X}}^{t_{1}^{X X}} d t+\int_{t_{2}^{X X}}^{t_{3}^{X X}} d t+\ldots+\int_{t_{k-1}^{X X}}^{t_{k}^{X X}} d t\right)+ \\
& +B_{\varepsilon_{1 \Pi}} \cdot\left(\int_{t_{0}^{1 \Pi}}^{t_{1}^{1 \Pi}} d t+\int_{t_{2}^{1 \Pi}}^{t_{3}^{1 \Pi}} d t+\ldots+\int_{t_{m-1}^{1 \Pi}}^{t_{m}^{1 \Pi}} d t\right)+\ldots+B_{2_{8 \Pi}} \cdot\left(\int_{t_{0}^{8 \Pi}}^{t_{1}^{8 \Pi}} d t+\int_{t_{2}^{8 \Pi}}^{t_{3}^{8 \Pi}} d t+\ldots+\int_{t_{p-1}^{8 \Pi}}^{t_{p}^{8 \Pi}} d t\right) \rightarrow G_{n \min },
\end{aligned}
$$

де $B_{2_{X X}}, B_{\tau_{1 \Pi}}, \ldots, B_{2_{8 \Pi}}$ - витрати палива за одиницю часу відповідно на холостому ходу, 1 -й, ..., 8-й позиціях контролера, кг/с;

$t_{X X}, t_{1 \Pi}, \ldots, t_{8 \Pi}-$ тривалість роботи гіркового локомотива протягом насуву та розпуску состава відповідно на холостому ходу, 1-й, ..., 8-й позиціях контролера, с;

$t_{0}^{X X}, t_{2}^{X X}, t_{k-1}^{X X}, t_{0}^{1 \Pi}, t_{2}^{1 \Pi}, t_{m-1}^{1 \Pi}, \ldots, t_{0}^{8 \Pi}, t_{2}^{8 \Pi}, t_{p-1}^{8 \Pi} ;$

$t_{1}^{X X}, t_{3}^{X X}, t_{k}^{X X}, t_{1}^{1 \Pi}, t_{3}^{1 \Pi}, t_{m}^{1 \Pi}, \ldots, t_{1}^{8 \Pi}, t_{3}^{8 \Pi}, t_{p}^{8 \Pi}-$ моменти часу початку і кінця роботи гіркового локомотива відповідно на холостому ходу, 1-й, .., 8-й позиціях контролера, с.

Враховуючи те, що

$$
\begin{aligned}
& \int_{t_{0}}^{t_{1}} d t=10^{3} \cdot \int_{V_{0}}^{V_{1}} \frac{d V}{Z\left(I_{1}^{\text {Hac }}, I_{2}^{\text {нac }}\right)}, \int_{t_{2}}^{t_{3}} d t=10^{3} \cdot \int_{V_{2}}^{V_{3}} \frac{d V}{Z\left(I_{1}^{\text {Hac }}, I_{2}^{\text {Hac }}\right)}, \\
& \int_{t_{4}}^{t_{5}} d t=10^{3} \cdot \int_{V_{4}}^{V_{5}} \frac{d V}{Z\left(I_{1}^{\text {нac }}, I_{2}^{\text {нac }}\right)}, \ldots,
\end{aligned}
$$

де $Z\left(I_{1}^{\text {нас }}, I_{2}^{\text {нас }}\right)=g^{\prime}(S) \cdot\left(f_{m}\left(V\left(I_{1}^{\text {нас }}, I_{2}^{\text {нас }}\right)\right)+I_{\text {екв }}\left(S, I_{1}^{\text {нас }}, I_{2}^{\text {нас }}\right)-\omega_{0}^{\text {лок }}\left(V\left(I_{1}^{\text {нас }}, I_{2}^{\text {нас }}\right)\right)\right.$ $\left.-\omega_{0}^{\text {coсm }}(S)-\omega_{c \kappa}\left(S, V\left(I_{1}^{\text {нас }}, I_{2}^{\text {нас }}\right)\right)-\omega_{c в}\left(S, V\left(I_{1}^{\text {нас }}, I_{2}^{\text {нас }}\right)\right)\right)$, цільова функція набуває такого вигляду: 


$$
\begin{aligned}
& G_{n}=10^{3}\left(B_{2_{X X}} \cdot\left(\int_{V_{0}^{X X}}^{V_{1}^{X X}} \frac{d V}{Z\left(I_{1}^{\text {Hac }}, I_{2}^{\text {Hac }}\right)}+\int_{V_{2}^{X X}}^{V_{3}^{X X}} \frac{d V}{Z\left(I_{1}^{\text {Hac }}, I_{2}^{\text {Hac }}\right)}+\ldots+\int_{V_{k-1}^{X X}}^{V_{k}^{X X}} \frac{d V}{Z\left(I_{1}^{\text {Hac }}, I_{2}^{\text {Hac }}\right)}\right)+\right. \\
& +B_{\tau_{1 \Pi}} \cdot\left(\int_{V_{0}^{1 \Pi}}^{V_{1}^{1 I}} \frac{d V}{Z\left(I_{1}^{\text {Hac }}, I_{2}^{\text {Hac }}\right)}+\int_{V_{2}^{1 I I}}^{V_{3}^{1 \Pi}} \frac{d V}{Z\left(I_{1}^{\text {Hac }}, I_{2}^{\text {Hac }}\right)}+\ldots+\int_{V_{m-1}^{1 I}}^{V_{m}^{1 I}} \frac{d V}{Z\left(I_{1}^{\text {Hac }}, I_{2}^{\text {Hac }}\right)}\right)+\ldots+
\end{aligned}
$$

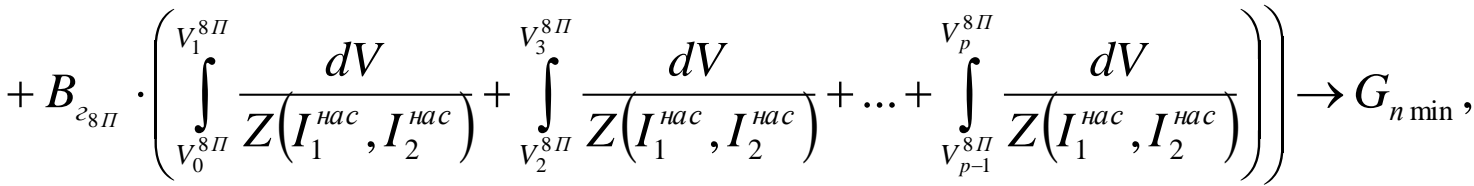

де $V_{0}^{X X}, V_{2}^{X X}, V_{k-1}^{X X}, V_{0}^{1 \Pi}, V_{2}^{1 \Pi}, V_{m-1}^{1 \Pi}, \ldots, V_{0}^{8 \Pi}, V_{2}^{8 \Pi}, V_{p-1}^{8 \Pi} ; V_{1}^{X X}, V_{3}^{X X}, V_{k}^{X X}$, $V_{1}^{1 \Pi}, V_{3}^{1 \Pi}, V_{m}^{1 \Pi}, \ldots, V_{1}^{8 \Pi}, V_{3}^{8 \Pi}, V_{p}^{8 \Pi}$ - швидкості составу у моменти часу початку і кінця роботи гіркового локомотива відповідно на холостому ходу, 1-й, ..,, 8-й позиціях контролера, м/с.

Задача визначення раціональних параметрів поздовжнього профілю насувної частини розв'язується при таких обмеженнях-нерівностях:

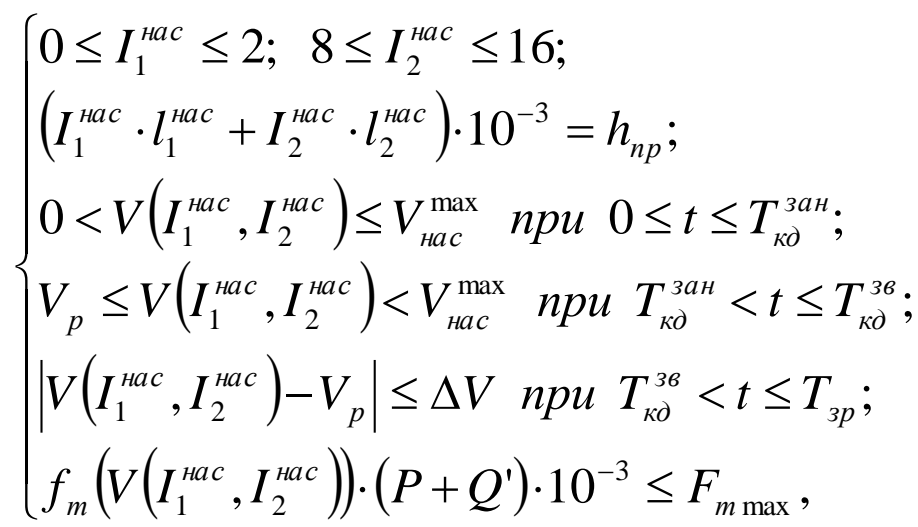

де $l_{1}^{\text {нас }}, l_{2}^{\text {нас }}-$ довжина відповідно першого і другого елементів поздовжнього профілю насувної частини, м;

$h_{n p}$ - задана профільна висота насувної частини, м;

$V_{\text {нас }}^{\max }$ - максимальна швидкість насуву состава на гірку, м/с;

$V_{p}$ - задана швидкість розпуску состава, $\mathrm{M} / \mathrm{c}$;
$T_{\kappa \partial}^{3 а н}, T_{\kappa \partial}^{3 в}-$ моменти часу відповідно зайняття і звільнення першою віссю состава контрольної дільниці (зони зменшення швидкості насуву состава до заданої швидкості розпуску), м/с;

$\Delta V$ - задане найбільше відхилення миттєвої швидкості состава від заданої швидкості розпуску, м/с;

$T_{\text {зр }}-$ момент закінчення розпуску состава, с; 
$P, Q^{\prime}$ - вага відповідно локомотива і состава, $\mathrm{H}$;

$F_{m \text { max }} \quad-$ максимальна сила тяги локомотива, $\mathrm{H}$.

При заданій профільній висоті насувної частини довжини першого i другого елементів поздовжнього профілю розраховуються за формулами

$$
\begin{gathered}
l_{1}^{\text {нас }}=\frac{1000 \cdot h_{n p}-I_{2}^{\text {нас }} \cdot l_{\text {нас }}}{I_{1}^{\text {нас }}-I_{2}^{\text {нас }}} ; \\
l_{2}^{\text {нас }}=l_{\text {нас }}-l_{1}^{\text {нас }},
\end{gathered}
$$

де $l_{\text {нас }}$ - довжина насувної частини, м.

Слід зазначити, що для розв'язання рівнянь (3) слід зробити припущення про постійність на кроці інтегрування складових диференціального рівняння (1).

Для визначення миттєвої сили тяги локомотива використано характеристики тепловоза ЧМЕ-3. У моделі вказані характеристики апроксимовані методом найменших квадратів такими залежностями:

$$
\begin{aligned}
& F_{k}(V)=70,07 \cdot e^{-0,31 \cdot V} \text { при позиції контролера } n_{\kappa}=1 ; \\
& F_{k}(V)=145-22,2 \cdot V \text { при } n_{\kappa}=2 \text { и } V \leq 1,8 ; \\
& F_{k}(V)=118,06 \cdot e^{-0,14 V} \text { при } n_{\kappa}=2 \text { и } V>1,8 ; \\
& F_{k}(V)=230-24,4 \cdot V \text { при } n_{\kappa}=3 \text { и } V \leq 4,3 ; \\
& F_{k}(V)=214,55 \cdot e^{-0,13 \cdot V} \text { при } n_{\kappa}=3 \text { и } V>4,3 ; \\
& F_{k}(V)=277-20,5 \cdot V \text { при } n_{\kappa}=4 \text { и } V \leq 4 ; \\
& F_{k}(V)=269,16 \cdot e^{-0,11 \cdot V} \text { при } n_{\kappa}=4 \text { и } V>4 ; \\
& F_{k}(V)=375-31,7 \cdot V \text { при } n_{\kappa}=5 \text { и } V \leq 3 ; \\
& F_{k}(V)=399,2 \cdot e^{-0,13 \cdot V} \text { при } n_{\kappa}=5 \text { и } V>3 ; \\
& F_{k}(V)=411,76-17,39 \cdot V-1,74 \cdot V^{2} \text { при } n_{\kappa}=6 \text { и } V \leq 4 ; \\
& F_{k}(V)=397,34 \cdot e^{-0,08 \cdot V} \text { при } n_{\kappa}=6 \text { и } V>4 ; \\
& F_{k}(V)=437,08-11,7 \cdot V-1,92 \cdot V^{2} \text { при } n_{\kappa}=7 \text { и } V \leq 4,5 ; \\
& F_{k}(V)=441,73 \cdot e^{-0,07 \cdot V} \text { при } n_{\kappa}=7 \text { и } V>4,5 ; \\
& F_{k}(V)=450,72-8,49 \cdot V-1,32 \cdot V^{2} \text { при } n_{\kappa}=8 \text { и } V \leq 6,3 ; \\
& F_{k}(V)=465,63 \cdot e^{-0,06 \cdot V} \text { при } n_{\kappa}=8 \text { и } V>6,3 .
\end{aligned}
$$

Задача визначення раціональних параметрів поздовжнього профілю насувної частини $\epsilon$ задачею нелінійного програмування 3 обмеженнями. Враховуючи складний аналітичний вигляд цільової функції, визначення ii похідних викликає певні труднощі. У зв'язку з цим пропонується для розв'язання вказаної задачі використати метод штрафних функцій. Вказана функція має такий аналітичний вигляд: 


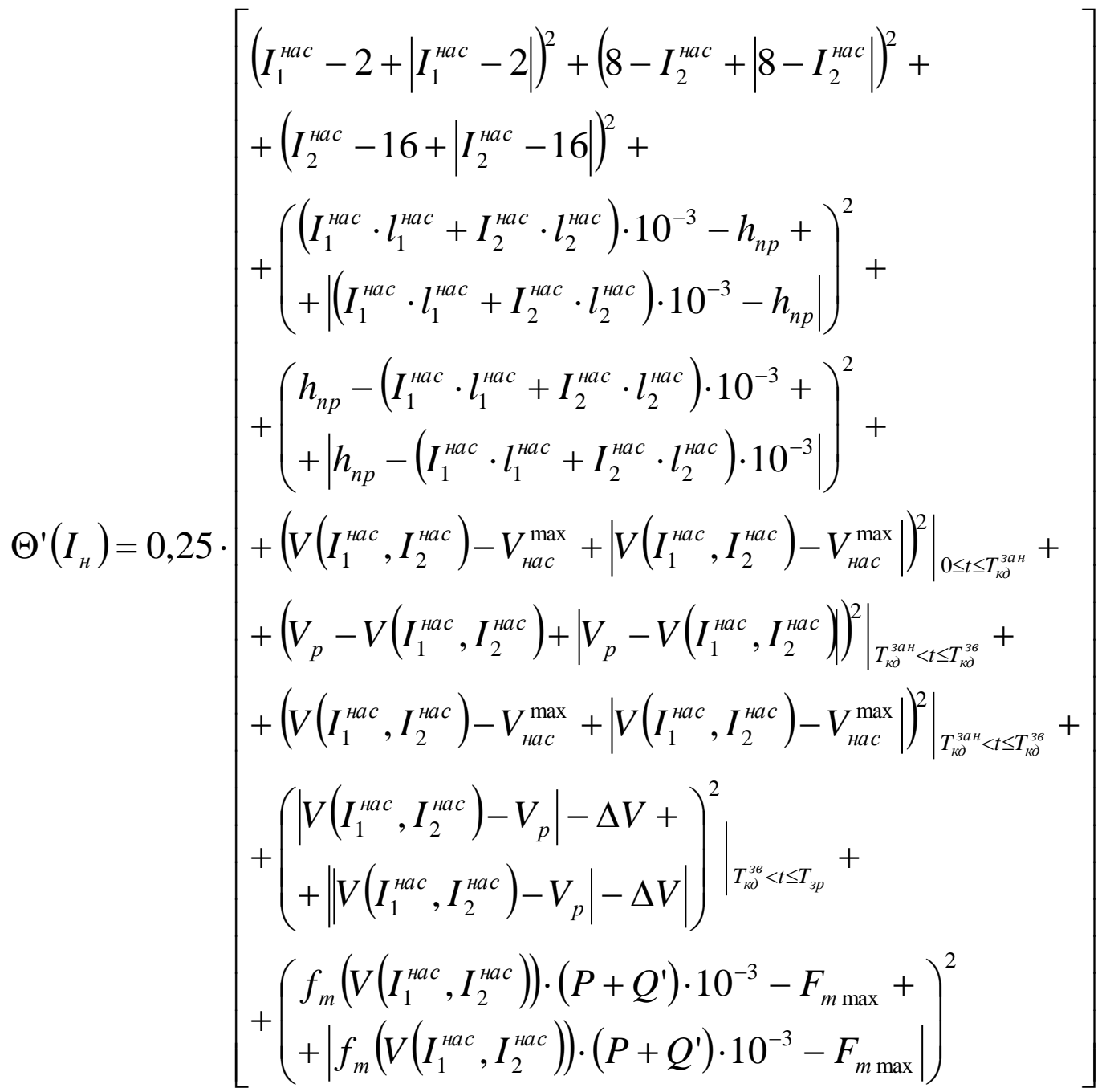

Зведемо задачу визначення раціональних параметрів поздовжнього профілю насувної частини до задачі мінімізації спеціальної функції:

$$
\begin{aligned}
& T^{\prime}\left(I_{H}, t\right)=G_{n}+t \cdot \Theta^{\prime}\left(I_{H}\right)= \\
& =10^{3}\left(B_{2_{X X}} \cdot\left(\int_{V_{0}^{X X}}^{V_{1}^{X X}} \frac{d V}{Z\left(I_{1}^{\text {Hac }}, I_{2}^{\text {Hac }}\right)}+\int_{V_{2}^{X X}}^{V_{3}^{X X}} \frac{d V}{Z\left(I_{1}^{\text {Hac }}, I_{2}^{\text {Hac }}\right)}+\ldots+\int_{V_{k-1}^{X X}}^{V_{k}^{X X}} \frac{d V}{Z\left(I_{1}^{\text {Hac }}, I_{2}^{\text {Hac }}\right)}\right)+\right. \\
& +B_{\tau_{1 \Pi}} \cdot\left(\int_{V_{0}^{1 I}}^{V_{1}^{1 I}} \frac{d V}{Z\left(I_{1}^{\text {Hac }}, I_{2}^{\text {Hac }}\right)}+\int_{V_{2}^{1 \Pi}}^{V_{3}^{1 \Pi}} \frac{d V}{Z\left(I_{1}^{\text {Hac }}, I_{2}^{\text {Hac }}\right)}+\ldots+\int_{V_{m-1}^{1 \Pi}}^{V_{m}^{1 I}} \frac{d V}{Z\left(I_{1}^{\text {нac }}, I_{2}^{\text {нac }}\right)}\right)+\ldots+ \\
& +B_{2_{8 \Pi}} \cdot\left(\int_{V_{0}^{8 I}}^{V_{1}^{8 \Pi}} \frac{d V}{Z\left(I_{1}^{\text {Hac }}, I_{2}^{\text {Hac }}\right)}+\int_{V_{2}^{8 \Pi}}^{V_{3}^{8 \Pi}} \frac{d V}{Z\left(I_{1}^{\text {Hac }}, I_{2}^{\text {Hac }}\right)}+\ldots+\int_{V_{p-1}^{8 I}}^{V_{p}^{8 I I}} \frac{d V}{Z\left(I_{1}^{\text {Hac }}, I_{2}^{\text {Hac }}\right)}\right)+ \\
& +t \cdot \Theta^{\prime}\left(I_{H}\right) \rightarrow \min .
\end{aligned}
$$


Процедура пошуку раціональних параметрів поздовжнього профілю насувної частини за методом штрафних функцій аналогічна процедурі пошуку раціональних параметрів профілю спускної частини, що наведена у роботі [9]. Відмінність процедур полягає тільки у тому, що при оптимізації профілю насувної частини не передбачається статистичне моделювання процесів насуву та розпуску составів, виходячи 3 прийнятого допущення про детермінованість параметрів метеорологічних умов.

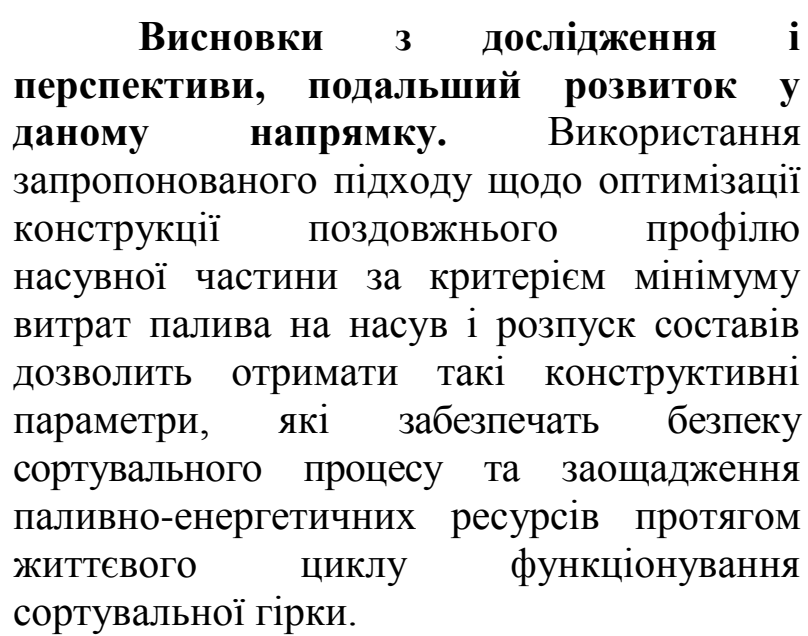

Висновки 3 дослідження і даному напрямку. Використання запропонованого підходу щодо оптимізації конструкції поздовжнього профілю насувної частини за критерієм мінімуму витрат палива на насув і розпуск составів дозволить отримати такі конструктивні параметри, які забезпечать безпеку сортувального процесу та заощадження паливно-енергетичних ресурсів протягом сортувальної гірки.

\section{Список літератури}

1. Данько, М.I. Наукові основи ресурсозберігаючих технологій при організації вантажних залізничних перевезень [Текст] : дис. ... д-ра техн. наук: 05.22.01 / М.I. Данько. Харків, 2005. - 357 с.

2. Топчієв, М.П. Удосконалення технології роботи технічних засобів сортувальних станцій на основі ресурсозбереження [Текст] : дис. ... канд. техн. наук: 05.22.20 / М.П. Топчієв. - Харків, 2004. - 246 с.

3. Похилко, С.П. Забезпечення ресурсозбереження шляхом удосконалення технології роботи технічних засобів підсистеми розформування сортувальних станцій [Текст] : дис. ... канд. техн. наук: 05.22.20 / С.П. Похилко. - Харків, 2005. - 273 с.

4. Бобровский, В.И. Совершенствование имитационной модели процесса надвига и роспуска составов на сортировочных горках [Текст]/ В.И. Бобровский, Е.Б. Демченко // Транспортні системи та технології перевезень: зб. наук. праць. - Дніпропетровськ: ДНУЗТ, 2012. - Вип. 3. - С. 5 - 9.

5. Павлов, В.Е. Проектирование сортировочных горок [Текст]/ В.Е. Павлов, М.М. Уздин, Ю.И. Ефименко. - Л.: ЛИИЖТ, 1987. - 97 с.

6. Основные требования к техническому оснащению сортировочных станций [Текст]: труды ВНИИЖТа. - М.: Трансжелдориздат, 1963. - Вып. 270. - 220 с.

7. Пригоровский, В.Ф. Выбор рациональных сортировочных устройств малой мощности на железнодорожных станциях [Текст]: автореф. дисс. ... канд. техн. наук. - М., 1962. -24 c.

8. Шипулин, А.П. Проектирование надвижной части сортировочных устройств с использованием ЭВМ для применения АЗСР [Текст]/ А.П. Шипулин // Вопросы совершенствования проектирования и использования устройств железнодорожных и промышленных узлов: труды МИИТа. - М., 1976. - С. 88 - 89.

9. Огар, О.М. Розробка процедури розрахунку раціональних параметрів поздовжнього профілю спускної частини сортувальних гірок [Текст] / О.М. Огар, Л.А. Страна, Л.В. Бригіна // Зб. наук. праць. - Харків: УкрДАЗТ, 2013. - Вип. 135. - С. 37-45.

Ключові слова: сортувальна гірка, поздовжній профіль, насувна частина, паливноенергетичні ресурси, гірковий локомотив. 


\section{Анотації}

Обгрунтовано критерій оптимізації поздовжнього профілю насувної частини сортувальної гірки. Наведено математичну модель визначення раціональних параметрів профілю за умови використання у гірковому технологічному процесі маневрових тепловозів.

Обоснован критерий оптимизации продольного профиля надвижной части сортировочной горки. Приведена математическая модель определения рациональных параметров профиля при условии использования в горочном технологическом процессе маневровых тепловозов.

The criterion of optimization of sorting hump slip-on part longitudinal profile is grounded. The mathematical model of profile rational parameters determination on condition of mobile diesel engines use in the hump technological process is resulted. 